\title{
Malaria in Rural Nigeria: Implications for the Millennium Development Goals
}

\author{
Olufunke A. Alaba \\ Department of Economics \\ University of Pretoria \\ Pretoria, South Africa \\ E-mail: funkeal@yahoo.com \\ and \\ Olumuyiwa B. Alaba \\ Department of Economics \\ BOWEN University \\ Iwo, NIGERIA \\ Olumuyiwa_alaba@yahoo.co.uk
}

\begin{abstract}
In recent years, there has been increase in human and financial commitments to malaria control, nationally and internationally, partly due to the need to meet the development targets set in the millennium development goals (MDGs). However, these efforts have not translated into significant decrease in the disease incidence and its impact in Nigeria. Using the cost of illness analysis, the paper found that an estimate of about $10 \%$ of gross domestic output of Oyo state is lost annually to malaria attack. This has serious implications for the achievement of development blueprint in the National Economic Empowerment and Development Strategies (NEEDS) and the MDG target. Effective control of malaria is capable of reducing household poverty, inequality, welfare and aggregate national development.
\end{abstract}




\section{Introduction}

The primary focus of the first and the sixth components of the millennium development goals (MDGs), adopted by the United Nations in 2000, is to solve the problems associated with diseases and poverty respectively. The first item of the MDGs aims to halt and afterwards begins to reverse the incidence of malaria and other major diseases by 2015. Also, the sixth of the listed objectives of the MDGs is to reduce to half, between 1990 and 2015, the proportion of people below absolute poverty level. Ever since the millennium development goals were set and globally adopted in principle and supported with huge human and financial commitments, only few of the malaria endemic countries could claim that various initiated strategies to combat a disease that has bedevilled Africa for more than 40 years since independence have had significant impact in rolling back the disease.

Despite various declarations by African governments in the 1990s and complementary effort promised in the main content of the Roll back Malaria Declaration in Abuja in 2000, malaria remains a major health challenge. About 107 countries and territories involving about 3.2 billion people are still at risk of malaria attack as at 2004 (World Health Organisation [WHO], 2005). Present estimates suggest that around 350-500 million clinical disease episodes occur annually (Bawah and Binka, 2005). Around $60 \%$ of clinical cases and over $80 \%$ of the deaths due to malaria occur in Africa south of the Sahara (Alaba, 2005).

The above has serious implication for economic growth and welfare. Malaria is responsible for an estimated average annual reduction of $1.3 \%$ in 
economic growth for those countries with the highest burden, Nigeria inclusive. The seemingly intractable trend of this ancient scourge has compounded the national and household poverty due to intensive loss of productive time to attack and death. A cause for worry at the moment is the growing resistance of the disease to cheap first line drugs and the need for the more expensive ACT combination therapy. Given that malaria is endemic throughout Nigeria, and that more than half the country's population are living below poverty line. Malaria incidence may increase significantly in Nigeria because many may not be able to afford the newly introduced drugs due to poverty.

The above will no doubt constrain the ability of the country to achieve the target set out in the NEEDS and the MDGs. The main focus of this paper is to examine the direct and the indirect impact of malaria on households in agricultural sector and determine its implication for the achievement of the millennium development goals 1 and 6 .

\section{The Epidemiology of Malaria in Nigeria}

Incidence of malaria varies by weather, which affects the ability of the main carrier of malaria parasites, anopheline mosquitoes, to survive or otherwise. Tropical areas including Nigeria have the best combination of adequate rainfall, temperature and humidity allowing for breeding and survival of anopheline mosquitoes. The burden of malaria varies across different regions of the world and even within a country. This is driven by the variation in parasite- vector-human transmission dynamics that favour or limit the transmission of malaria infection and 
the associated risk of disease and death. Of the four species of Plasmodium that infect humans-P. falciparum, P. vivax, P. malariae and P. oval. Plasmodium falciparum causes most of the severity and deaths attributable to the disease, which is most prevalent in Africa south of the Sahara, where Nigeria has the largest population.

Country-specific evidence shows that Nigeria has the largest population at risk of malaria in Africa and therefore most vulnerable to the risk of missing MDGs target. The disease, malaria, is a major health problem in the country, with stable transmission throughout the country. It accounts for about 50 percent of out-patient consultation, 15 per cent of hospital admission, and also prime among the top three causes of death in the country (National Malaria Control Plan of Action 1996 to 2001). More importantly, it is a social and economic problem, which consume about US\$3.5 million in government funding and US\$2.3 million from other stakeholders in various control attempts in 2003 (World Health Organisation [WHO], 2005).

Approximately $50 \%$ of the Nigerian population experience at least one episode per year. However, official estimate suggests as much as four bouts per person per year on the average (WHO, 1995 and 2002). The trend is rapidly increasing due to the current malaria resistance to first line anti-malarial drugs (WHO, 2000). The magnitude of incidence and death due to it is a multiple of all other tropical diseases put together. It is responsible for over $90 \%$ of reported cases of tropical disease in Nigeria (Alaba and Alaba 2003). The above suggests that 
malaria could be the largest contributor to total disease burden and productivity losses resulting from major tropical diseases in the country. Evidence on Nigeria given by the malaria report 2005 shows that malaria incidence throughout the country had been on the increase over the years ranging between 1.12 million at the beginning of 1990 and 2.25 million by the turn of the millennium 2000 and 2.61 million in 2003.

The disease carries with it two categories of costs; morbidity and mortality costs. Malaria morbidity affects households' welfare (through families' allocation to treatment and prevention of the disease), and decline in productivity, through lost time. In the case of mortality, losses to households include lost of future income and cumulative investment on the dead due to malaria.

\section{Malaria: The Micro-Macro Linkage}

Malaria has implications for the development of household members and the country through various mechanisms. One, malaria impairs the ability of people to work hard by losing productive time during care-giving activities, while adults with malaria severely compromise household/family resources, as their capacity to work, earn income and save for their families is reduced. Added to this, the illness generates new financial demands to cover medical treatment, threatening food supply and in extreme cases funeral expenses. Two, it affects child's development and compromise future productive capacity due to absenteeism from school associated with malaria attack. Also, malaria is known to be a main cause of anaemia, epileptic convulsions, growth faltering, and neurological squeal. These are 
all likely to affect children's performance at school. Three, in the agricultural sector/rural area, peak of malaria transmission has been found to coincide with the peak of planting and harvest seasons when demand for labour is suppose to be high. With this vast expanse of land goes uncultivated and substantial harvest are lost because workers are sick.

This flow of the consequences of malaria from the micro level to the macro level is depicted in figure 1 modified by the author from Castro and Mokate 1988. 


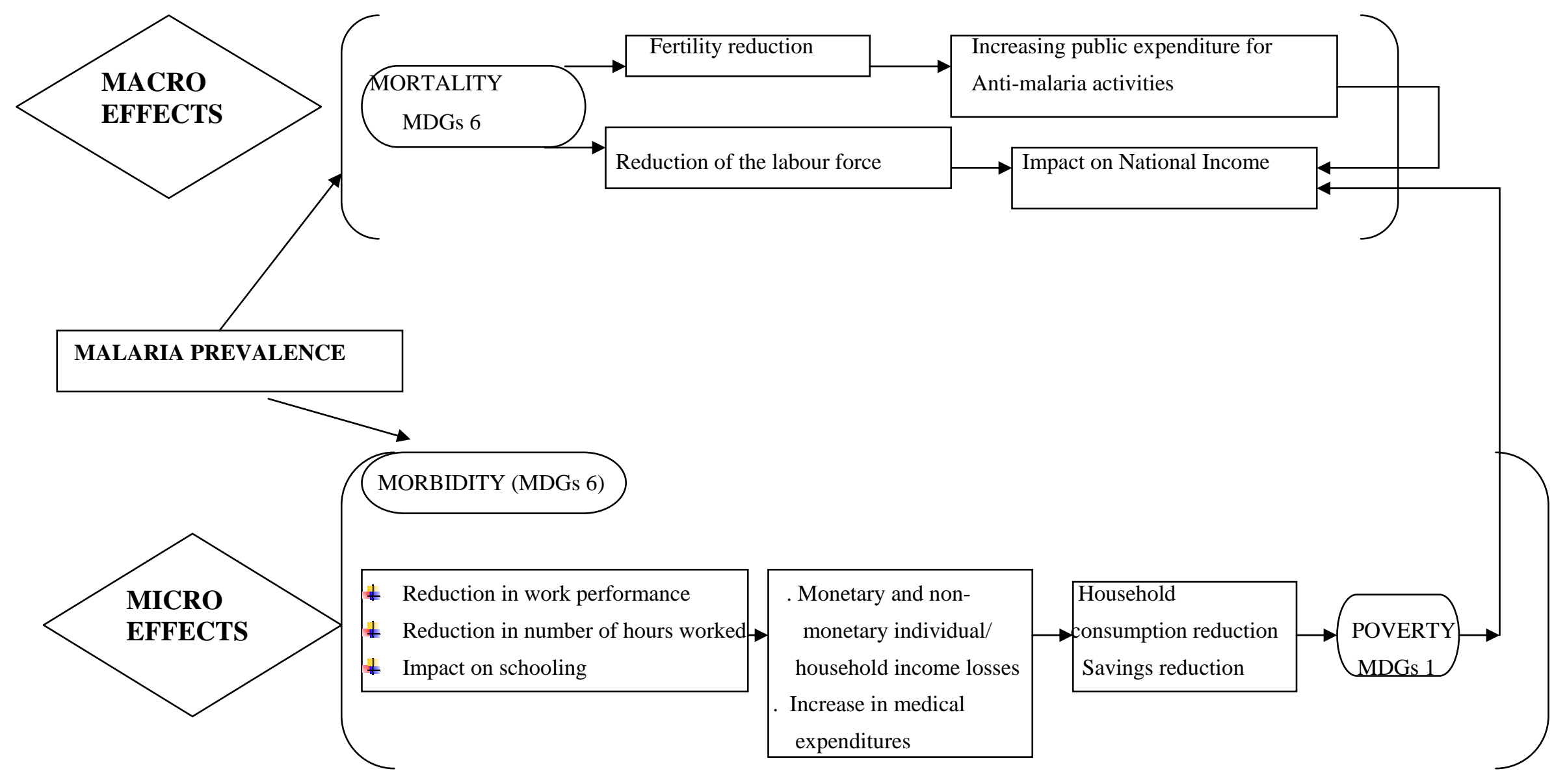

Figure 1: Malaria: Micro and Macro Linkages

Source: Author's modification of Castro and Mokate (1988). 


\section{Theoretical Framework: Health, Labour Supply and Productivity}

In a standard neo-classical framework labour will be hired up to the point where the product of the output price and marginal product of the incremental unit of labour just equals his or her wage rate. Implicit from this is the assumption that marginal product of labour is usually positive. Taken as given in this framework is the fact that an individual worker who experiences onset of health impairment or absolute illness becomes less productive or unproductive respectively while he is working at his or her current occupation (DeLeire and Manning, 2004).

Two channels of effect on individuals' income are established in economic theory. These are the role of health over wage rate and the part it plays in the decisions relating to supply of labour and, decisions on how many hours of labour to supply. According to Alves et al. (2003) healthy individuals, are expected to possess a higher level of human capital, would be more productive than those with poor health. At the household level, where fundamental decisions are made, malaria strip families of their main sources of financial and non-financial resources.

For the affected individuals, the consequences include emotional distress caused by illness and sometimes death. Associated with this is the critical need to care for those infected and to find ways of replacing their contributions to the household and the community. A decrease of labour productivity resulting in loss of income, reduction of savings, and food, reduced support for the elderly; death of adult children, and the growing burden of orphanage is left to the family and concerned friends which finally trickle down to the national economy. This translates into substantial direct, indirect, intangible costs, 
and life time loss of earnings, all of which determine poverty and welfare status of the households and finally the economy at large.

\section{Methodology}

This study draws on the human capital theory, which has been widely used to assess the productivity losses from illness or injury as measured by income forgone due to morbidity, disability and mortality. The method we found simple and appropriate for this purpose is the cost of illness (COI) approach. This is meant to assess the effects of malaria on productivity which translates into loss of income and finally poverty. The Cost of illness (COI) method is the summation of the direct cost of illness and the indirect cost of illness. The indirect cost of illness is the opportunity cost of time lost to sickness and care giving. The time cost is defined as the sum of the opportunity cost of wages forgone by the sick individual due to illness, and the opportunity costs of healthy household members' time spent on treating or attending to the sick person or accompanying them for treatment. This was equated to the opportunity cost of time with the average cost of labour, approximated by the estimated average wage rate (Alaba, 2005). The assumption is that the value of a day of work lost could be treated as the gain that would result if malaria were reduced or eliminated after taking care of substitution of labour in the household. The direct cost of illness of malaria includes all out of pocket expenses from the entire household during an attack of malaria. The total cost of illness of malaria is the summation of the two costs, which gives the total implication for economic resource loss in the rural sector of Oyo State calculated based on the 1991 census figure which is 3.1million.

\section{Variables and Data}


The primary indicator for health is calculated as the number of days lost to malaria by the adults in the household in the last four weeks referenced from the survey period. The measure of income loss is based on the productivity loss of the household members by both the sick and the care-givers measured by household hourly wages. The hourly wage rate measure is derived by dividing the total calculated household monthly earnings by the given number of hours worked in the month by the productive force in the household.

Data for the study was collected using multi-stage-sampling techniques. Three health zones from Oyo State namely Ibadan, Ogbomoso, and Oyo were used as the base strata, from where 4 local governments namely Akinyele, Surulere, Afijio and Oluyole were randomly selected for the study. Using structure questionnaires and 4 weeks recall period, 416 malaria affected households were collated and used for the analysis. The outcomes from the sample were used to project the implications for the rural population of Oyo, State in Nigeria.

\section{Results}

\section{Malaria and Labour Force Participation}

The most significant loss associated with malaria is borne indirectly by the households affected by malaria. These labour participation losses associated with an episode of malaria are reported in table 1 . The average number of workdays lost per malaria episode by the productive forces in the household was 16 and 15 days in the agrarian households and the non-agricultural segment respectively for all households.

Analysis of the net days lost shows that the family reduces her participation in the labour market by 10 and 8 days for the agriculture and non-agriculture segments. Although the mark-up to the net represents loss attributable to need to hire the substitute labour, the net effect reduces work-days lost to the primary family. This result indicates that the 
households in the agriculture segment could not afford to lose as many days as the counterparts in the non-agriculture segment. Stern (1996) using data for the US finds that care-giving reduces the probability of labour force participation by 18 to $20 \%$ not withstanding the sex of the care-giver.

Table 1. Labour Time Loss per Bout of Malaria Per Household (Average Number of Days)

\begin{tabular}{|l|l|l|l||}
\hline & AGRICULTURE & NON- & TOTAL \\
\hline $\begin{array}{l}\text { (1)Patients Lost } \\
\text { Workdays }\end{array}$ & 16 & 15 & SAMPLE(N=416) \\
\hline $\begin{array}{l}\text { (2) Productive days gained } \\
\text { Gains in household due to } \\
\text { Labour substitution by } \\
\text { hired labour }\end{array}$ & 11 & 10 & 13 \\
\hline $\begin{array}{l}\text { Net direct days lost(1) - } \\
\text { (2) }\end{array}$ & 5 & 5 & 4.5 \\
\hline $\begin{array}{l}\text { (3) Primary caregiver's lost } \\
\text { Workdays }\end{array}$ & 5 & 3 & 4 \\
\hline $\begin{array}{l}\text { Net Number of Work Days } \\
\text { Lost:[ (1) - (2) + (3) ] }\end{array}$ & 10 & 8 & 8.5 \\
\hline \hline
\end{tabular}

\section{Monetary Cost of Malaria}

\section{Direct Costs of Illness}

The direct cost of illness (COI) is the out-of-pocket expenditures on treatment, and cost of transportation (round-trip) associated with receiving medical care. In this case, treatment costs include expenses on consultation (including laboratory test where relevant) and purchase of drugs. Analysis of total sick households shows that, all households irrespective of sector of employment bore an average direct cost of N357.21. 
Disaggregation by sector of employment reveals that average direct COI is N421.92 and N291.30 in households involved in agriculture and those in the non-agriculture segment respectively.

Table 2: Elements of Direct Cost of Illness per Episode

\begin{tabular}{||l|l|l|l||}
\hline & AGRICULTURE & NON- & TOTAL \\
& & AGRICULTURE & SAMPLE(N=416) \\
\hline Treatment Costs & 315.24 & 207.42 & 261.93 \\
\hline Transportation Costs & 106.68 & 83.88 & 95.28 \\
\hline Direct COI(\#) & $\mathbf{4 2 1 . 9 2}$ & $\mathbf{2 9 1 . 3 0}$ & $\mathbf{3 5 7 . 2 1}$ \\
\hline \hline
\end{tabular}

\section{Indirect Cost of Illness}

It is important to fashion out a modest and theoretically acceptable measure of loss to malaria in calculating the indirect COI in monetary terms. The measure of indirect COI adopted in this respect is the use of the average daily earnings of the workers. Using this, the magnitude of monetized indirect COI in agricultural sector is estimated to be $\$ 9,375.00$ per malaria episode (Table 3). This result shows that the effect of malaria on the productive time of households is in multiples of the out of pocket expenses called direct cost incurred by the household members. 
Table 3: Indirect Cost of days lost to malaria

\begin{tabular}{||l|l|l|l||}
\hline & \multicolumn{2}{|l||}{ ALL HOUSEHOLDS N=416 } & TOTAL SAMPLE \\
\hline & Agric & Non-agric & \\
\hline $\begin{array}{l}\text { 1. Average daily } \\
\text { earnings (1) }\end{array}$ & 937.50 & 1050.20 & 911.02 \\
\hline $\begin{array}{l}\text { 2. Net loss days } \\
\text { by household }\end{array}$ & 10 & 8 & 8.5 \\
\hline $\begin{array}{l}\text { 3. Monetary cost } \\
\text { of loss days to } \\
\text { malaria(1) (1) }\end{array}$ & 9375.00 & 8400.96 & 7743.67 \\
\hline $\begin{array}{l}\text { 4. Indirect Cost } \\
\text { of malaria() }\end{array}$ & $\mathbf{9 3 7 5 . 0 0}$ & $\mathbf{8 4 0 0 . 9 6}$ & $\mathbf{7 7 4 3 . 6 7}$ \\
\hline
\end{tabular}

\section{Total Cost of Malaria}

Table 4 shows the total cost of malaria, which is the sum of the direct COI and the indirect COI. Out of the total costs associated with the attack of malaria, the indirect cost associated with attacks is not less than 95\% in all segments. 
Table 4: Total Cost per Episode of Malaria in a Household

\begin{tabular}{|c|c|c|c|c|c|c|c|c|}
\hline \multirow[t]{3}{*}{ COSTS } & & & & & & & & \\
\hline & \multicolumn{2}{|c|}{$\begin{array}{l}\text { Agricultural } \\
\text { Activities }\end{array}$} & \multicolumn{2}{|c|}{\begin{tabular}{|l|} 
Non-agricultural \\
Activities
\end{tabular}} & \multicolumn{2}{|c|}{ Total sample } & \multicolumn{2}{|c|}{$\begin{array}{l}\text { Total } \\
\text { Population(Rural } \\
\text { Oyo State) }\end{array}$} \\
\hline & $\begin{array}{l}\text { Naira } \\
\text { (N) }\end{array}$ & $\%$ & $\begin{array}{l}\text { Naira } \\
\text { (A) }\end{array}$ & $\%$ & $\begin{array}{l}\text { Naira } \\
\text { (A) }\end{array}$ & $\%$ & $\begin{array}{l}\text { Naira } \\
\text { (N) }\end{array}$ & $\%$ \\
\hline $\begin{array}{l}\text { Direct } \\
\text { Cost }\end{array}$ & 421.92 & 4.31 & 291.30 & 3.35 & 357.21 & 4.4 & $\begin{array}{l}246.0 \\
\text { million }\end{array}$ & 5 \\
\hline $\begin{array}{l}\text { Indirect } \\
\text { Cost }\end{array}$ & $9,375.00$ & 95.69 & $8,400.96$ & 96.65 & 7743.67 & 95.6 & $\begin{array}{l}5.3 \\
\text { billion }\end{array}$ & 95 \\
\hline $\begin{array}{l}\text { Total } \\
\text { Cost of } \\
\text { Illness }\end{array}$ & $9,769.93$ & 100 & $8,692.26$ & 100 & 8100.88 & 100 & $\begin{array}{l}5.6 \\
\text { billion }\end{array}$ & 100 \\
\hline
\end{tabular}

\section{Conclusions}

The labour market represents the avenue where the abundant resources of human beings (i.e.labour) are traded and rewarded. Individuals and households health status often have a serious implication on participation in the market and in the long run, welfare and poverty level. The paper, using cost of illness approach, examines the impact of malaria on households' income and national income and welfare. The outcome of this analysis suggests that incidence of malaria in rural sector alone reduced Oyo State’s aggregate domestic income by about 10 per cent. Considering the positions of the component states that makes up the entity called Nigeria, in actualizing the bottom-up approach to development and attainment of the MDGs, similar trend in all States of the 
federation may spell doom for the Nigerian economy. Also, if we extend our analysis to other sectors of the economy the impact may have more significant effect on revenue profile, and by implication the means by which the government is able to fulfill her responsibility status and thus meeting the set target relating to the MDGs. 


\section{References}

Alaba A.Olufunke (2005) Malaria and Rural Household productivity in Oyo State. A P.hD thesis submitted in the Department of Economics, University of Ibadan.

and Olumuyiwa Alaba (2003), Malaria in children: implications for the productivity of female caregivers in Nigeria, selected paper for the 2002 annual conference of the Nigerian Economic Society.

Alves L. F., M.V. Andrade and P.B.R. Macedo (2003) Health and labour market in Brazil. Mimeograph

Bawah, A.A and F.N.Binka (2005), 'How many years of life could be saved if malaria were eliminated from a hyperendemic are of Northern Ghana, population Council Working PaperNo. 203

Castro E.B and K.M. Mokate (1988), "Malaria and its socio-economic meanings: The Study of Cunlay in Columbia, in Alandro N.H and Patricia Rossenfield ed. Economics, Health and Tropical Disease, Manila Univ. of Phillipines.

DeLeire T. and W. Manning (2004), “Labour market costs of illness: prevalence matters”, Health Economics 13: 239-50

World Health Organisation (2005), World Malaria Report, Geneva

World Health Organisation (2002) Malaria desk situation analysis - Nigeria.

World Health Organisation, (2000) “ Severe and complicated malaria”. Trans $R$ Soc Trop Med Hyg 94(suppl)

(1995), Action Plan for Malaria Control (1995-2000), WHO, Preventive action and intensification of the struggle against malaria control, mimeograph. 